\title{
The Functional Design and Application of Computerized Accounting System in the University Financial Management
}

\author{
Yan Wang \\ Department of Economics and management, Tianjin Electronic Information College, Tianjin,300350, \\ China \\ ywang@126.com
}

Keywords: Computerized accounting; The university financial management; Functional design and application

\begin{abstract}
Computer management accounting data processing speed and accuracy, data processing program and standardization, automation, improve accounting information timeliness, reliability and relevance. In university financial management, the computer is used to manage finance, and help the financial staff to account and process data, it makes financial work to be more convenient and shortcut. In this paper, the computerization of the relevant theory and development of technology to seriously study the basis of practical experience in colleges and universities in the computerized accounting carried out a detailed analysis of the current college financial processing business. A viable computerized accounting system is designed and applied to the university financial management.
\end{abstract}

\section{Introduction}

To adapt to the fast-changing market economy, we must use modern management means. While for modern management, it is necessary to get accurate and timely accounting information. The use of computer in the field of accounting can quickly process the data and output some logical reasoning, so the resulting accounting information is more accurate and timely, conducive to make timely decision by managers. With the rapid development of China's economic system and market economy, the development of computer network technology, the establishment of computerized accounting network system can quickly realize the sharing of data and delivery of information at home and abroad quickly, not only meet the needs of management information for units, but also provide good opportunities of carrying out management, analysis, forecasting and decision-making using the internal accounting information and external information for the financial management personnel, accounting management personnel, analysis personnel and unit leaders.

Computerized accounting refers to the accounting software prepared by the professional staff, by the accounting staff and the relevant operators to operate the computer to replace the artificial work for completing the accounting work, that is to say, it is a process of using computer to replace manual accounting, counting, reimbursement, analysis and application of all kinds of accounting information, which consists of the organization and planning of Computerized accounting work, the establishment of computerized accounting information system, the formation of computerized accounting management system, the training of accounting personnel, the management of computerized accounting information system, computerized auditing, etc.

The emergence of accounting computerization is a revolution in accounting technology. It improves the efficiency and the quality of accounting work, promotes the standardization of accounting work, and lays the foundation for the informationization and modernization of accounting management. Computerized accounting frees accounting staff from heavy manual work and becomes the main tool of accounting work. At the same time, it has a profound impact on traditional accounting work due to the use of computer and financial software. During several years of development of computerized computerized in China, software technology become more mature, the scope of application is also quite extensive, it can be said that where there are accounting work there is computerized accounting. 
Based on the characteristics of accounting computerization in colleges and universities, this paper studied the function design and application of computerized accounting information system in financial management of colleges and universities, so as to help the financial staff more convenient and quick to deal with financial data by using computer software in school financial work, Easier to complete the financial work.

\section{The Characteristics of College Computerized Accounting Software}

College computerized accounting software has its own characteristics, college financial management are quite different from financial management, the specific performance is as follows:

(1) Broad range. we need to use computerized accounting software in the university teaching and research, daily things, logistics and other aspects.

(2) Strong comprehensive. Compared with the financial management software of the enterprise, the computerized accounting software of colleges and universities needs to carry out accounting work in different departments and different activities, and the wide range of fund sources also makes the computerized accounting of colleges and universities more comprehensive.

(3) High sensitivity. The business activities of colleges and universities are ultimately evaluated based on the economic and social benefits. Therefore, the data have certain sensitivity, such as the evaluation of the grade and effect of scientific research, the cost of student training, the size of social service benefit, etc. Those need to be embodied through the computerized accounting system.

\section{The Overall Function Design of System}

Design Outline. Design outline is an important part of system design. In this system, the design outline mainly includes:

(1) Design all kinds of design specifications. In the process of the development of the system, through the analysis of the needs of the system, we can determine the most suitable design, in the meanwhile, stipulate coding standards of all the design documents.

(2) Establish the overall design structure of the system. In this system, the basic computerized accounting subsystem is mainly set up for the accounting information system. Subsystem is used mainly for the basic settings of the financial treatment, the processing of the certificate, cashier, bookkeeping management and final processing, and finally carry out financial analysis, and further make the financial statements.

(3) Establish the treatment between the functional modules. In the design process of the functional module, we must first clarify the relationship between the various functional modules, in the design of background database table, this kind of relationship should be reflected to facilitate the front desk to quote the various forms of reference.

(4) Design data structures. The structure of data in the accounting information system involved in storing are designed, including date items and their attributes of each data structure, the main foreign key of each data structure, index file and logical view, etc. In the design of system database, relational database model is applied, and the system code design is a very important data structure. Due to the particularity of the accounting information system, the internal forms are inextricably linked. Therefore, the good or bad of the design of the form structure in the whole system will directly affect the service function of the accounting information system.

The Overall Function Design of System. College accounting information system is a very large system, in the specific design and implementation process, only the financial processing subsystem was designed. The system from the beginning of the new set of books to the final treatment, achieving to convert the manual financial processing to computerized processing basically. In this system, for the basic setting of accounting needs, such as the setting of accounting subjects, the maintenance of the certificate category, the information maintenance of the department and the units, user management and other aspects of the basic settings. The application of accounting information system can improve the efficiency of accounting work, accuracy and timeliness of accounting information greatly, achieving the data sharing to a certain degree. In the computerized 
accounting system, the entry of the data includes manual mode and computer system automatic mode, such that the entry of initial balance when the first time to use the system is manual mode, that is, the manual data will be introduced into the system database. And then the final processing of each accounting period is automatically completed by the computerized accounting system. System specific functions were shown in Fig. 1.

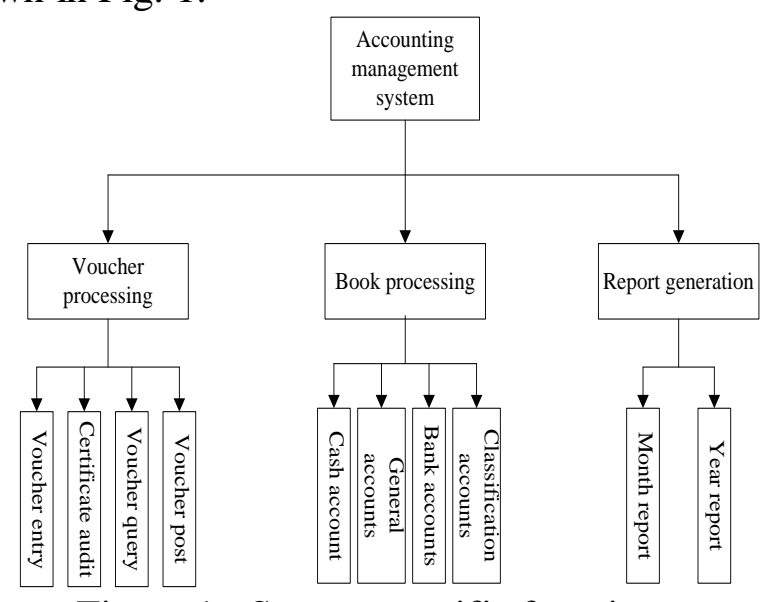

Figure 1. System specific functions

Book processing: mainly according to the needs of unit, you can establish and use a different set of books.

Voucher processing: the entry, audit and posting of the certificate to achieve automation, in the audit process, mainly whether the amount of borrower is equal to the audit or not, the user can achieve the audit of a single voucher and voucher period batch audit according to the need. In the process of posting, the voucher of failure to pass the review cannot be posted, In this module, the query function of voucher is also set up, the user can achieve batch query for a single voucher and voucher period according to the need. Finally, the category management module of voucher is also set and the basic settings of the type of voucher are set.

Report generation: In this module, the main set of monthly reports, the annual report.

\section{System Application and Security Risk Prevention}

System Application. The first use of college accounting information system, the user will carry out a large number of initialization work. The system initialization is the basis of the use of the system, opening up the working environment for the future use of the system. The specific process of application system is as follows:

(1) Initialization of funding index.

Before the start of operation, the requirement of "initial funding" work. The task is to mainly enter the balance in the deadline to the computer, forming the initial balance of the projects. And then we can carry out the project accounting work on this basis.

(2) Certificate management.

Registration of bookkeeping vouchers is required prior to registration of books. In the computerized system, the accuracy and completeness of the data depends on the accuracy and completion of the entry of the voucher.

(3) Cashier review.

Cashier review is mainly the checking function on the accounting vouchers involved in the cash bank's income and expenditure. Only after finishing the completion of the review work, we can carry out cashier work. This function is checked by the cashier based on the original document and the account in the system. The main object of the check is whether the cashier's cash account is correct, and the unsuccessful data needs to be re-entry by the accountant.

(4) Bank reconciliation 
Bank reconciliation refers to check bank deposit daily records and bank statements one by one at regular intervals, to find the subjects having not entered into account, preparing the "bank balance adjustment table", adjusting the school bank deposit daily balance to have the same results with bank statement balance. At the time of reconciliation, the school account and the bank account can be automatically tested on a number of times. You can also make manual adjustments on the basis of automatic reconciliation. The accounts manually adjusted can also be checked automatically to test the correctness.

Security Risk Prevention. The security of college accounting information system refers to the ability of the system to maintain normal and stable operation. The security risk of accounting information system refers to the ability of security protection become weaker due to human factor or non-human factors, so as to cause the information distortion, theft, such as loss of unit funds and property, the possibility of occurrence that system hardware and software can not run normally. For the accounting information system security, we should take the following countermeasures:

(1) Strengthen the management of the data input link. The date should be tested before the data being input in the system, the input data, codes and others should be checked to ensure the legitimacy and authenticity, besides, data input personnel should be managed.

(2) Impose the necessary control measures on the software function to protect the security of accounting data. Design accounting organization procedures adapting to computerized accounting processing, check the input system data, code and others, increase the necessary restrictions, enhance the necessary protection features and prompts functions.

(3) Modify the restrictions function

Modify the function can be user-friendly, improve the system's practicality, but also increase the system's insecurity. Therefore, it is necessary to restrict the modification function in the accounting processing.

(4) Establish safety measures to prevent the virus

In order to improve the security capabilities, ensure reliable operation of the network system, enhance network security immunity, we must take some measures. Currently widely-used password control, data encryption, callback device firewall technology are belong to that. When establishing prevention security measures to virus, the following aspects should be done: (1) adhere to use genuine software, do not use pirated or unknown software and e-mail. (2) regularly backup disk data and software. (3) when we are not sure whether the computer brings a virus, but want to read the floppy disk data, the floppy disk should write in protection state. (4) often carry out virus detection on the computer hard drive and floppy disk, establish the precaution measures for hackers.

\section{Summary}

In the time of rapid development of information technology, with the increasingly frequent financial activities of colleges, college computerized accounting system has become an indispensable part of the university management funds. As the computerized accounting system master and control the financial platform for the operation of colleges, so it plays a pivotal role. The real-time processing and effective records can be achieved for college's all kinds of financial activities through college accounting information system. Users can directly access the system through the network, to extract and deal with relevant data according to the need. In addition, we can obtain historical financial reports at any time. The college computerized accounting system can ensure the accuracy, completeness, truthfulness and reliability of accounting information, and reduce the loss caused by human factors because the system's built-in processes and methods conform to the existing laws and regulations.

\section{Reference}

[1] Zangxiu Qing, He Yufen.Technology security and defense of network accounting. Accounting communications. 2009,2:46-52. 
[2] Bushman, R.A Smith. Transparency, Financial Accounting Information and Corporate Governance. FRBNY Economic Policy Review. 2003,3:15-22.

[3] Microstructural Evolution and Thermal Stability of Ultra-fine Grained Al-4Mg Alloy by Equal Channel Angular Pressing. Journal of Materials Science \& Technology, 2014, (03):46-58.

[4] Shao Dan.From Accounting Computerlization to Modern Accounting Information System. China Management Informationlization. 2006,2:12-20.

[5] Shan Binglei.The Security-risks and prevention of Network Accounting Information System. Chinese Enterprise Accounting of Villages and towns. 2009,5:89-98. 